\title{
Analyses of Composite Beams and Frames at Elevated Temperature
}

\author{
T. MORITA \\ Construction Engineering Research Department, Institute of Technology \\ Shimizu Corporation \\ 3-4-17, Etchujima Koto-ku, Tokyo 135, Japan
}

T. WAKAMATSU

Department of Architecture, Faculty of Science and Technology

Science University of Tokyo

2641, Yamazaki Noda-shi, Chiba 278, Japan

H. UESUGI and $H$. SAITO

Department of Architectural Engineering, Faculty of Engineering

Chiba University

$1-33$, Yayoicho Chiba-shi, Chiba 260, Japan

\begin{abstract}
This paper presents analyses of composite beam which is composed of $\mathrm{H}$-section steel and reinforced concrete slab. Analyzed models were simply supported beams and $\mathrm{H}$-shaped structural frames which were composed of 2-story columns and 1-span beam. In analyzing simply supported beams, some other factors (for example, thickness of fire protection, width of slab etc...) were considered. In analyzing $\mathrm{H}$-shaped structural frames, two models were considered. One model has composite beam, and the other model has H-section steel beam only. From the results of these analyses, it is concluded that the fire resistance of the structural frame with $\mathrm{H}$-section steel beam and the structural frame with composite beam is almost the same.
\end{abstract}

KEYWORDS: fire behavior, thermal stress, thermal deformation, steel structure, reinforced concrete slab, composite beam, inside temperature

\section{INTRODUCTION}

During the last two decades, analyses of steel frame structures exposed to fire have been advanced. Though, in general, a frame of an actual steel structure building is connected with reinforced concrete slab, its effect is not taken into account in most analyses of structural behavior in fire.

Steel frame members, beam and column, are covered with fire protection so that the steel should not reach a high temperature, at which the mechanical properties (elastic modules, yield stress and strength), decrease. However, reinforced concrete slab is not covered with fire protection, if the thickness from surface to reinforcement is considered adequate $[1,2]$. In these conditions, when exposed to fire, the temperature of the slab near the soffit is higher than that of steel members. Especially in regard to the beam, it can be assumed that the behavior of steel frame structure is influenced by the difference of temperature between slab soffit and steel beam $[3,4]$. 
In this investigation of the influence of reinforced concrete slab in steel frame structure, the composite beam composed of $\mathrm{H}$-section steel and reinforced concrete slab is considered. Analyses consist of (a)calculation of inside temperature of structural member depending on fire temperature-time curve and (b)analysis of structural behavior in elasto-plastic range at the temperatures obtained from step(a). Analyzed models are simply supported beams and $\mathrm{H}$ shaped structural frames which are composed of 2-story columns and 1-span beam. In analyzing simply supported beams, some factors (for example, thickness of fire protection, width of slab etc...) are considered. And, in analyzing $\mathrm{H}$-shaped structural frames, two models, one of composite beam and one of $\mathrm{H}$-section steel beam, are considered.

\section{CALCULATION}

\section{Calculation Methods}

Calculation of Inside Temperature of Structural Member. The fire severity as heat load to a structure is generally obtained for each fire compartments. In this paper, however, the standard temperature-time curve prescribed in ISO 834 is applied as the fire temperature-time curve.

Inside temperature of a structural member as a function of time is calculated by "a finite difference method" $[5,6,7]$. The inside temperature is calculated for a two dimensional cross section of each member. The cross section of member is divided into subslices, and temperature of each subslice is constant during a time increase. Generally, thermal properties, thermal conductivity and specific heat, of the member's composite materials are dependent on temperature. Useful thermal property data are shown in reference[8]. In the reference these thermal properties are assumed to be second degree functions of temperature. In this paper, thermal properties of materials are quoted from this reference. Latent heat of moisture evaporation in composite materials must be considered. Some assumptions are introduced in calculating latent heat. In the actual case of exposure to fire, moisture moves in the material, and because of inside pressure of the material, moisture evaporation does not start at precisely 100 degrees centigrade. But, in the calculation of temperature, the following two main premises are assumed. One is that moisture does not move in material. The other is that moisture evaporation occurs at precisely 100 degrees centigrade. By the latter assumption, moisture in subslices decreases at every time step, after its temperature reaches 100 degrees centigrade. And when quantity of moisture decreases to $0 \%$, the temperature of subslices starts rising again.

Calculation of Structural Behavior. Thermal stress and deformation analyses of structural members and frames in fire are carried out by using the computer program "Fires-Frame I"[9]. This program applies "a non-linear direct stiffness formulation coupled with a time step integration" [10]. To apply this method, a structural member is divided longitudinally into segments, and the cross section of each segment is divided into subslices. It is convenient to use the same subslices for temperature calculation and structural calculation. The analysis of structural behavior is carried out by using thermal conditions obtained from the calculation of temperature.

\section{Calculated Models}

Simply Supported Beams. 10 models are discussed in this paper. All models consisting of simply supported beams whose spans are $2,000 \mathrm{~mm}$ are shown in TABLE 1. Each beam is exposed to fire on its bottom and sides. For example, the cross section of Model-A is shown in FIGURE 1 . The beams are longitudinally divided into 8 segments of equal length. The cross sections of the slabs are divided into 16 meshes (direction of thickness) and 3 meshes (direction of width). In the cross section of $\mathrm{H}$-section steel, flange is divided into 3 subslices, and web into 8 subslices. Model- $\mathrm{L}$ and Model- $\mathrm{N}$ are H-section steel beams only. Model-F and 
TABLE 1. Models of Simply Supported Beams

\begin{tabular}{|c|c|c|c|c|c|}
\hline Model & $\begin{array}{c}\text { Thickness } \\
\text { of } \\
\text { Slab } \\
\text { (mm) }\end{array}$ & $\begin{array}{l}\text { Width } \\
\text { of } \\
\text { Slab } \\
\text { (mm) }\end{array}$ & $\begin{array}{l}\text { Upper } \\
\text { Reinforce- } \\
\text { ment } * 1 \\
(\mathrm{~mm})\end{array}$ & Load & $\begin{array}{l}\text { Thickness } \\
\text { of } \\
\text { Fire Protection } \\
(\mathrm{mm})\end{array}$ \\
\hline $\bar{A}$ & 120 & \multirow{3}{*}{1000} & D10-@100 & \multirow{5}{*}{ N/A } & \multirow{6}{*}{$\begin{array}{c}\text { Sprayed } \\
\text { Rock Wool *5 } \\
50\end{array}$} \\
\hline B & & & N/A & & \\
\hline$\overline{\mathrm{C}}$ & 150 & & \multirow{6}{*}{ D10-@100 } & & \\
\hline $\bar{D}$ & \multirow{5}{*}{120} & 500 & & & \\
\hline $\mathrm{E}$ & & 2000 & & & \\
\hline $\bar{F}$ & & \multirow{3}{*}{1000} & & *3 & \\
\hline $\bar{G}$ & & & & \multirow{3}{*}{ N/A } & 30 \\
\hline$\overline{\mathrm{H}}$ & & & & & 70 \\
\hline $\mathrm{L}$ & \multirow{2}{*}{\multicolumn{3}{|c|}{$\begin{array}{c}\text { N/A *2 } \\
\text { (Not Applicable) }\end{array}$}} & & \multirow[t]{2}{*}{50} \\
\hline $\mathrm{N}$ & & & & *4 & \\
\hline
\end{tabular}

*1 Cover (concrete surface to reinforcement) is $30 \mathrm{~mm}$. All models have lower reinforcement (D10-@100).

*2 Model-L and Model-N are beam without reinforced concrete slab.

$* 3$ Vertical load $-277.53 \mathrm{kN} * 2, * 6$

*4 Vertical load $-181.13 \mathrm{kN} * 2, * 6$

* 5 Sprayed Rock Wool is composed of rock wool and cement. Spraying to steel, water is added to these materials. The distribution ratio of this material is as follows, rock wool : $60-75 \%$, cement $25-40 \%$.

* 6 Location of loads is an each side at a distance of $\mathrm{L} / 4$ from the middle of span (where $\mathrm{L}$ is span of beam).

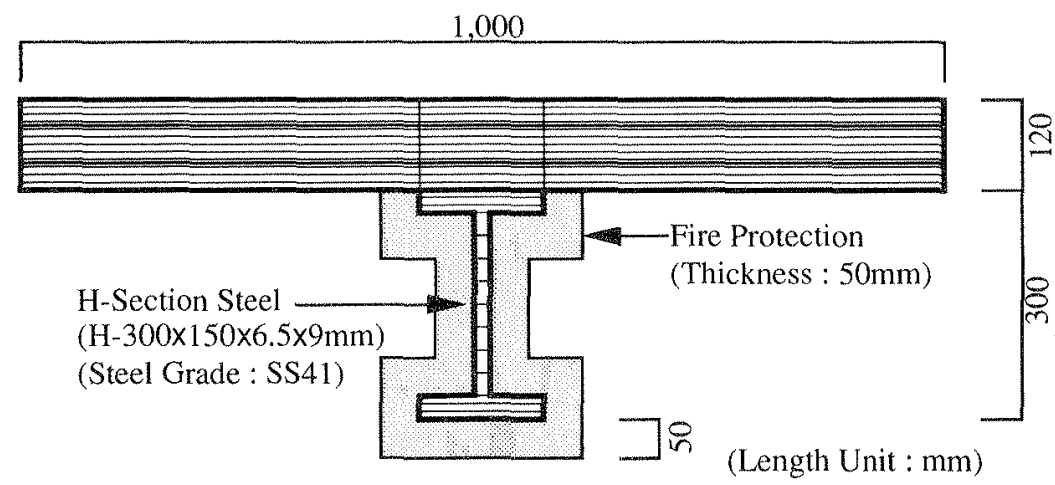

FIGURE 1. Cross Section Model of Composite Beam (Model-A)

Model- $\mathrm{N}$ are loaded to produce $80 \%$ of yielding stress in the middle span of the $\mathrm{H}$-section beam.

H-Shaped Structural Frames. FIGURE 2 shows a H-shaped structural frame cut out from an actual steel structure building. Bending deformation of upper edges of columns in upper story is restricted, and all deformation of lower edges of columns in lower story is restricted completely. 2 frame models are calculated. TABLE 2 shows specification of the models. Model-O is the structural frame with $\mathrm{H}$-section steel beam. Model-P is the structural frame with composite beam. The beams are longitudinally divided into 12 segments and columns into 7 segments. In the calculations, columns in lower story and beam were assumed to be exposed to fire. The lower column is heated from surroundings, and the beam is heated on its bottom and sides by fire. Equal loads is considered for both models. 


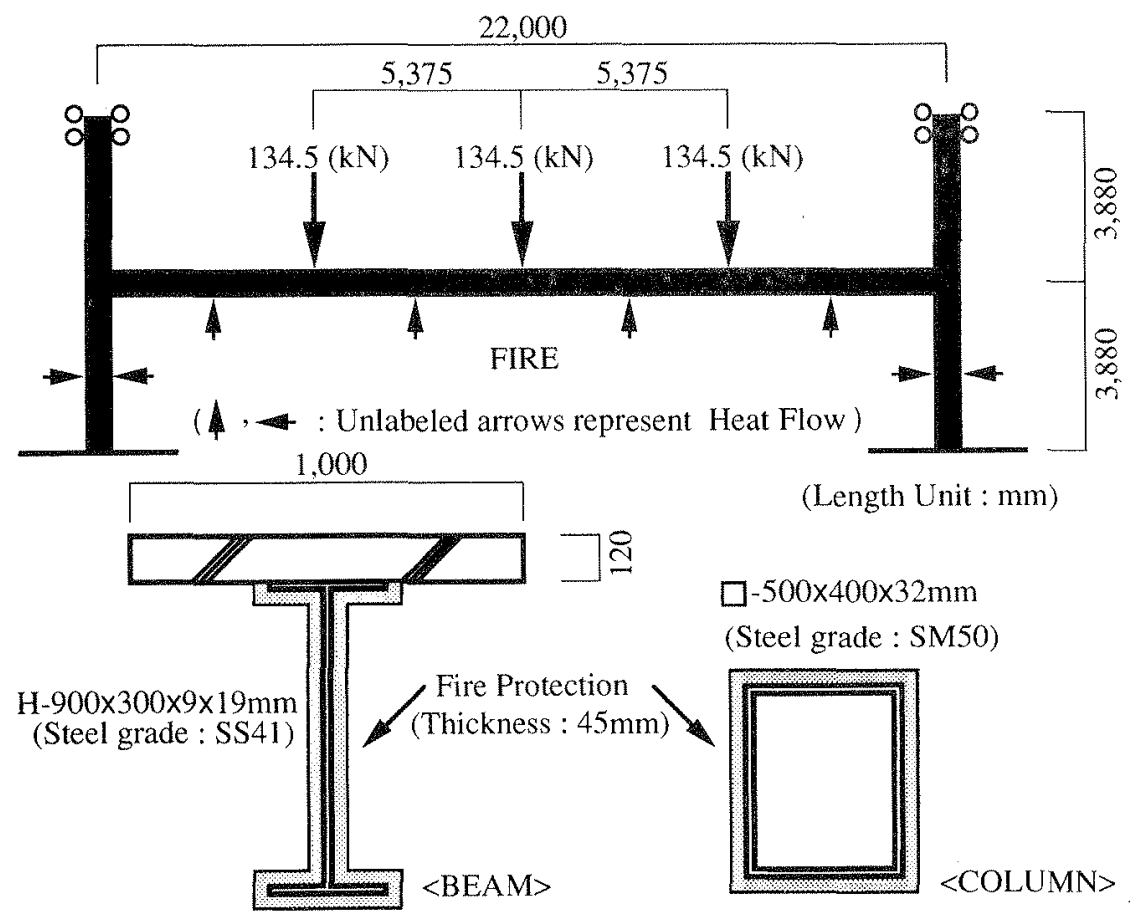

FIGURE 2. H-Shaped Structural Frame

TABLE 2. Models of H-Shaped Structural Frames

\begin{tabular}{|c|c|c|c|c|c|}
\hline Item & $\begin{array}{c}\text { Thicckness } \\
\text { of } \\
\text { Slab } \\
(\mathrm{mm}) \\
\end{array}$ & $\begin{array}{l}\text { Width } \\
\text { of } \\
\text { Slab } \\
\text { (mm) } \\
\end{array}$ & $\begin{array}{c}\text { Reinforce- } \\
\text { ment } \\
* 1 \\
(\mathrm{~mm}) \\
\end{array}$ & Load & $\begin{array}{c}\text { Thickness } \\
\text { of } \\
\text { Fire Protection } \\
(\mathrm{mm})\end{array}$ \\
\hline$\overline{\mathrm{O}}$ & \multicolumn{3}{|c|}{ N/A (Not Applicable) } & \multirow{2}{*}{$\begin{array}{c}\text { Actual } \\
\text { Live Load }\end{array}$} & \multirow{2}{*}{$\begin{array}{c}\text { Sprayed } \\
\text { Rock-Wool } \\
45\end{array}$} \\
\hline$\overline{\mathrm{P}}$ & 120 & 1000 & $\begin{array}{c}\text { D10-@100 } \\
\text { (double) }\end{array}$ & & \\
\hline
\end{tabular}

*1 Cover (concrete surface to reinforcement) is $30 \mathrm{~mm}$.

Assumptions. The assumptions of the analysis in this paper are as follows.

- Member is uniformly exposed to fire so that longitudinal temperature distribution is uniform.

- The percentages of moisture content in concrete and fire protection are $5 \%$.

- Mechanical properties of steel are quoted from reference[9]. Grade of H-section steel is SS41.

The Stress-Strain relations are shown in FIGURE 3.

- Compressive strength of concrete is $20.6 \mathrm{~N} / \mathrm{mm}^{2}$ at room temperature.

- Creep and shrinkage of concrete are ignored.

- Coefficient of thermal expansion of concrete is quoted from reference[10].

- Stress-Strain relations of concrete are assumed as FIGURE 4.

- Effective structural slab width exposed to fire is not sure presently. In this paper, $1,000 \mathrm{~mm}$ is used as basic slab width. (Effects of slab width are investigated in the analyses of simply supported beams.) 


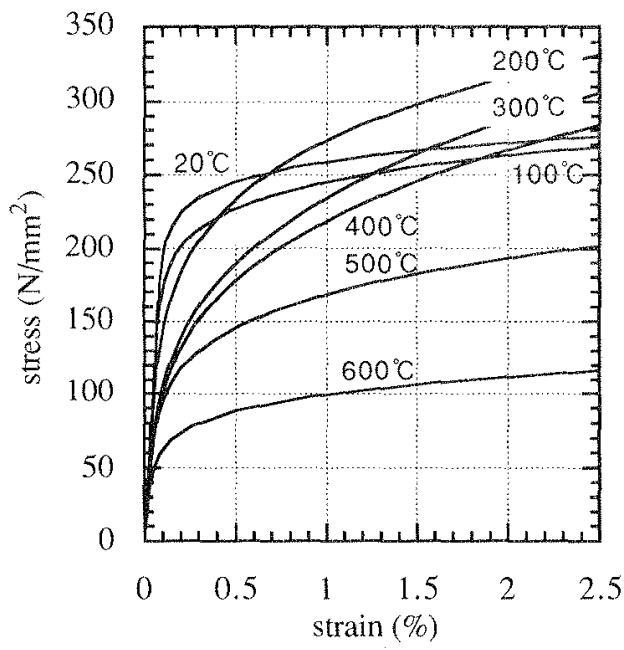

FIGURE 3. Stress-Strain Curve of Steel (SS41) [9]

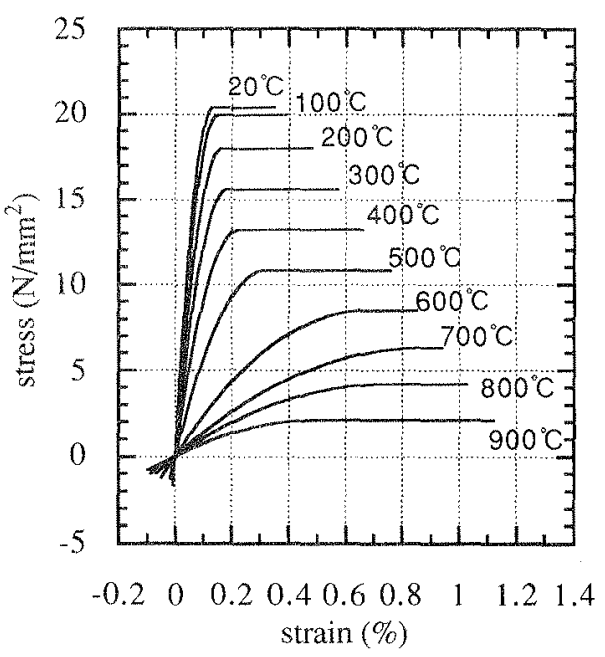

FIGURE 4. Stress-Strain Curve of Concrete

\section{RESULTS AND CONSIDERATIONS}

\section{Results of Simply Supported Beams}

Temperature Distribution in Cross Section of Beams. FIGURE 5 and FIGURE 6 show the inside temperature-time curve for Model-A as an example. The highest temperatures in $\mathrm{H}$ section steel occurred in the lower flange, followed by the web and then the upper flange. The temperature in the upper flange is influenced by moisture evaporation in the reinforced concrete slab. Temperature distribution in the cross section of the slab protected from direct exposure to fire by $\mathrm{H}$-section steel beam is lower than that of slab whose soffit is directly exposed to fire. While these two tendencies appeared in the other models, they were less appearance for models that provided less protection.

General Structural Behavior of Unloaded Simply Supported Beams. FIGURE 7 shows deflection at the middle of span of unloaded simply supported beams. When exposed to fire, the middle of span of the composite beams initially moves upward. This behavior is caused by the temperature distribution in the cross section of the composite beam. From the beginning of exposure to fire, the temperature of slab soffit rises, the slab elongates longitudinally, and the temperature of $\mathrm{H}$-section steel covered with fire protection does not rise as quickly. On the other hand, the middle of span of the beam without slab, Model-L, moves downward from the beginning of fire exposure, because thermal elongation appears directly corresponding to temperature distribution in the $\mathrm{H}$-section steel.

Comparison of Model-A,B and C(Influence of upper reinforcement). Upward deflection of Model-B appears larger than that of Model- $\mathrm{A}$ and $\mathrm{C}$. Concerning downward deflection, it can be said that more effective upper reinforcement makes more downward deflection.

Comparison of Model-A, D and E (Influence of slab width). The wider the slab is, the larger the upward deflection. The wider slab shows the larger rate of increase in downward deflection. Because the reinforcement per unit cross section is the same in all three models, upward deflection will be influenced by the ratio of slab width to cross sectional area of $\mathrm{H}$ section steel, and the rate of increase of downward deflection will be influenced by the ratio of strength of upper reinforcement to cross sectional area of $\mathrm{H}$-section steel. 


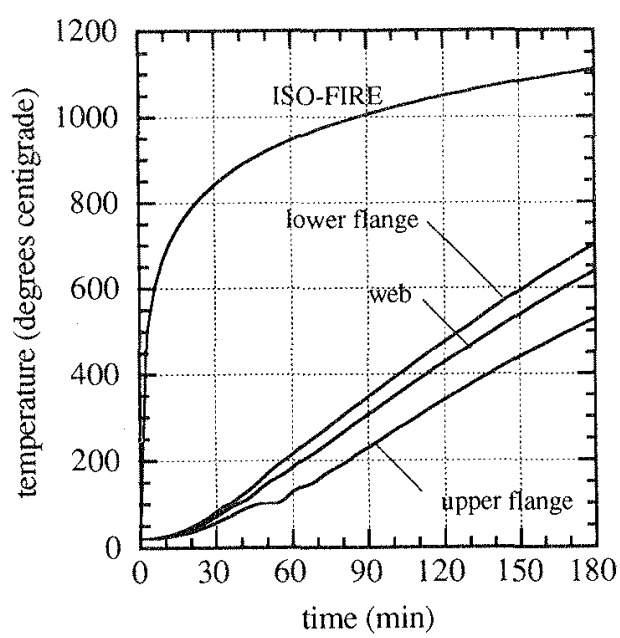

FIGURE 5. Temperature-Time Curve of H-Section Steel (Model-A)
- - : The part of slab whose soffit is directly exposed.

- The part of slab on upper flange.

$5,35,85,115$ : Distance from the soffit (unit : $\mathrm{mm}$ )

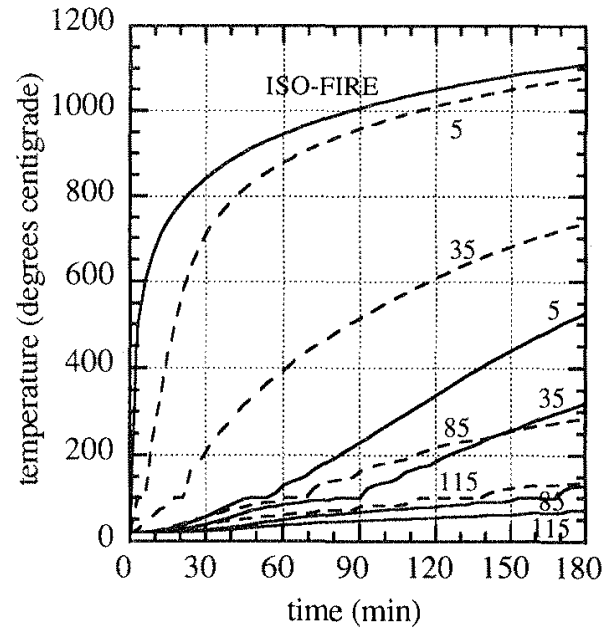

FIGURE 6. Temperature-Time Curve of Concrete Slab (Model-A)

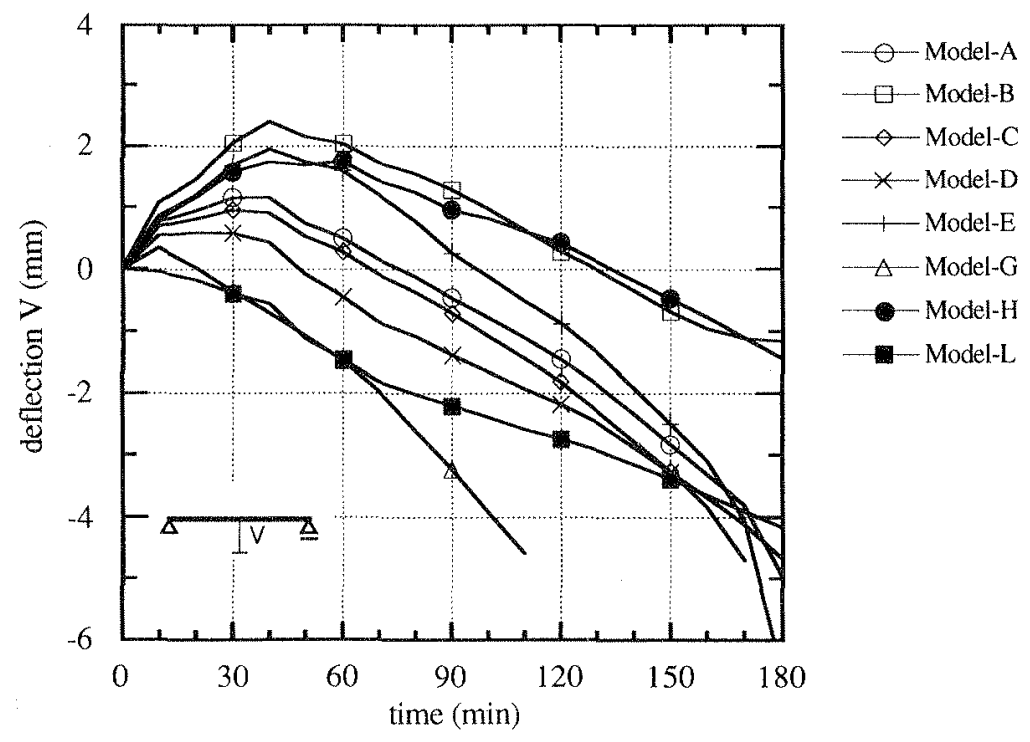

FIGURE 7. Deflection at the Middle of Span for Unloaded Beams 
Comparison of Model- A, G and $\mathrm{H}$ (Influence of thickness of fire protection). Regarding deflection at the middle of span, the thicker the fire protection is, the larger the upward deflection. And the thinner the fire protection is, the larger the downward deflection and rate of increase of downward deflection.

Loaded Simply Supported Beam. FIGURE 8 shows deflection at the middle of span and elongation of beam for Model-F and Model- $\mathrm{N}$. Though the downward deflection at the middle of span of the H-section steel beam is larger than that of the composite beam, rates of increase of downward deflection are almost the same. In this case, $80 \%$ of the yielding stress is produced in the middle of span of beams by the vertical load, and the vertical load for composite beam (Model-F) is greater than that for $\mathrm{H}$-section steel beam (Model- $\mathrm{N}$ ). In case of a simply supported beam, if the vertical load is the same, it is found that a composite beam is more advantageous than $\mathrm{H}$-section steel beam even in fire. But, in the case of composite beam, the calculation shows that compressive stress produced by vertical load concentrates in the cross sectional area in the lower part of slab whose soffit is directly exposed to fire. It can be seen that the strength of $\mathrm{H}$-section steel of the composite beam decreases, structural behavior for the composite beam would be much the same as for the H-section steel beam only. The elongation of the composite beam is greater than that of the $\mathrm{H}$-section steel beam as shown in FIGURE 8.

\section{Results of H-Shaped Structural Frames}

Deformation. FIGURE 9 and FIGURE 10 show the inside temperature-time curve for the beams of $\mathrm{H}$-shaped structural frame. FIGURE 11 shows structural deformation of $\mathrm{H}$-shaped structural frames. Progressive deformation of Model-O and $\mathrm{P}$ are much the same. But Horizontal deformation " $U$ " of Model-P is greater than that of Model-O.

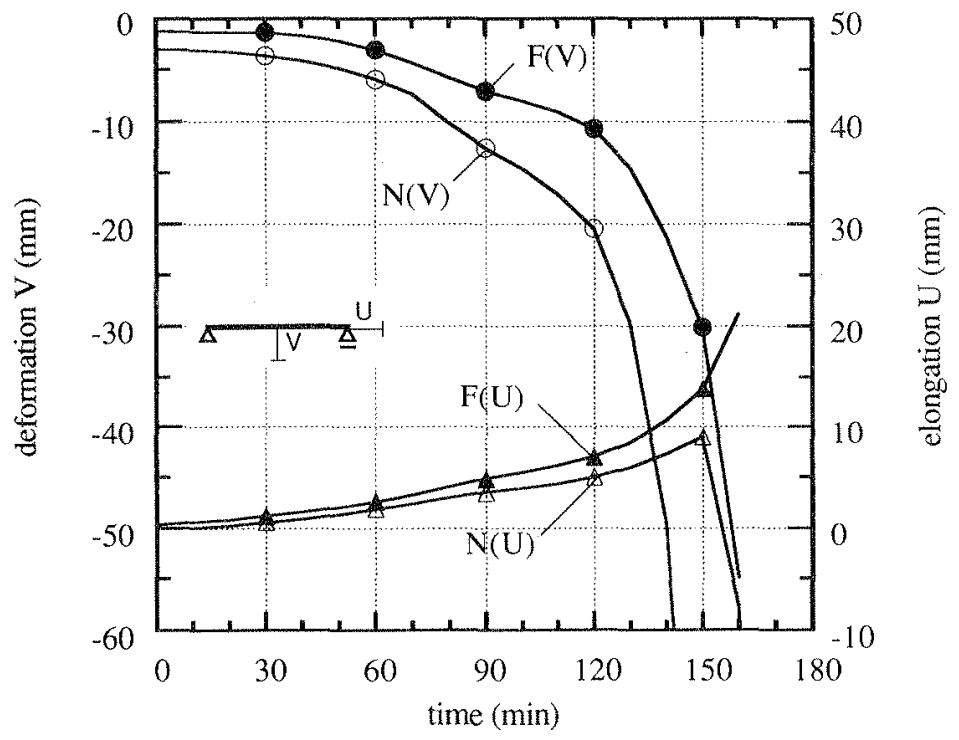

FIGURE 8. Deflection at the Middle of Span and Elongation for Loaded Beams 


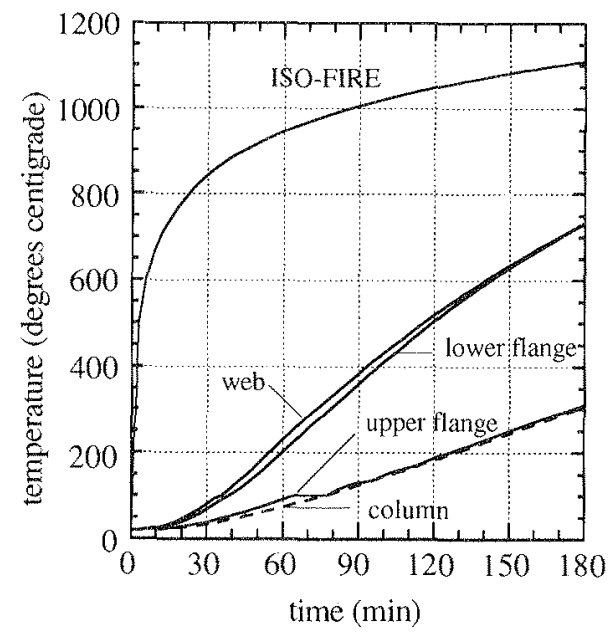

FIGURE 9. Temperature-Time Curve of $\mathrm{H}$ Section Steel and Column(H-shaped frame)
- - - : The part of slab whose soffit is directly exposed The part of slab on upper flange.

$5,35,85,115$ : Distance from the soffit (unit : mm)

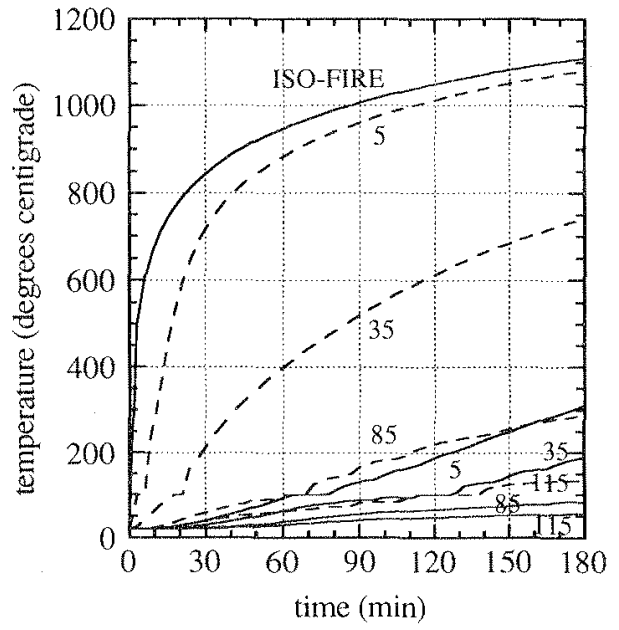

FIGURE 10. Temperature-Time Curve of Concrete Slab (H-shaped frame)

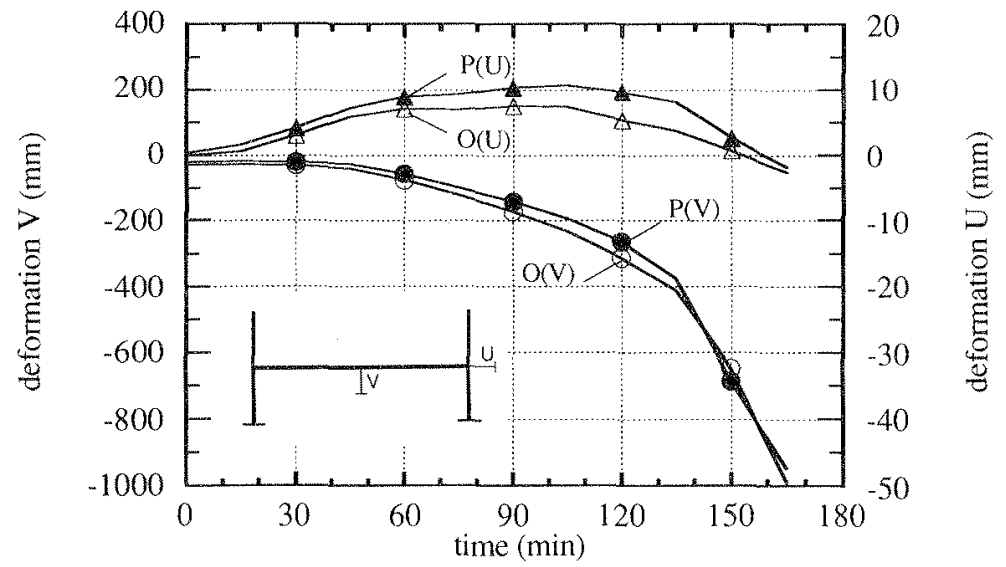

FIGURE 11. Deformation of H-Shaped Structural Frames

Bending Moment in Heated Column. FIGURE 12 shows development of bending moment in the heated columns. It must be noted that yielding moment and plastic moment in FIGURE 12 were obtained from the average temperature of heated column at each time step.

The bending moment for the $\mathrm{H}$-section steel beam of Model-O is less than that of the composite beam of Model-P, and only in the case of Model-P does the bending moment in the heated column reach yield moment. Bending moment in the columns increases to 90 minutes in the case of Model-O and 115 minutes in the case of Model-P. 


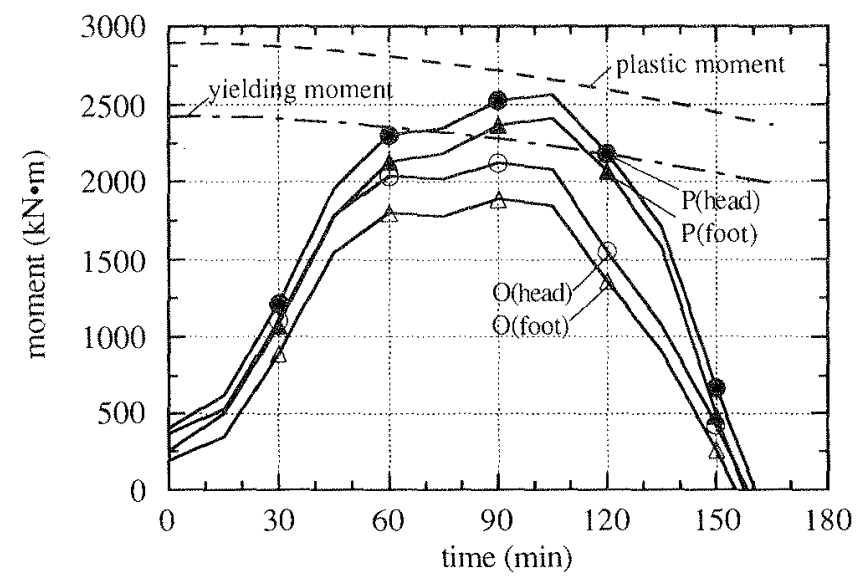

FIGURE 12. Development of Bending Moment in Heated Columns

Bending Moment in Beam at End of Span. FIGURE 13 shows development of bending moment in the beams. It must be noted that yielding moment and plastic moment in FIGURE 13 was obtained from the average temperature of $\mathrm{H}$-section steel beam at each time step and slab effect was not included.

The bending moment at the end of the $\mathrm{H}$-section steel beam span is greater than that of the composite beam, because flexural rigidity of the composite beam is greater than that for $\mathrm{H}$ section steel beam. In the case of Model-P, the bending moment decreases at the beginning of fire exposure, because composite beams will bend upwards due to inside temperature distribution. At 45 minutes, it seems that yielding occurs in the lower edge of each beam in an end of span, and after that, compressive yield area in the cross section increases to the upper flange of each beam, and compressive strength of steel decreases with rising temperature. By this progress, plastic hinges are produced at the ends of span, and the beams act as a simply supported beam. Behavior at the ends of span of the models is much the same, because concrete almost does not bear tension stress. But, if the amount of upper reinforcement is greater than that of this case, the difference between steel beam and composite beam would appear more clearly than this case.

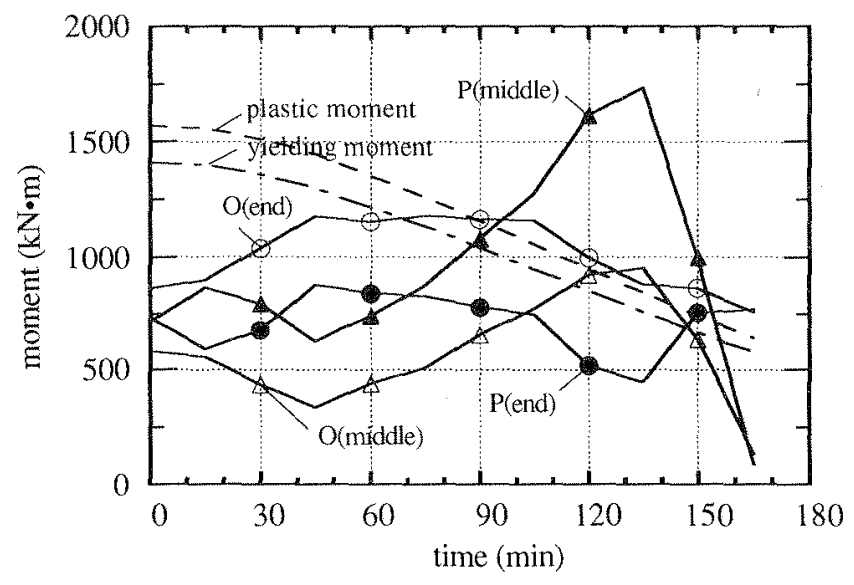

FIGURE 13. Development of Bending Moment in Heated Beams 
Bending Moment in Beam at Middle of Span. Bending moment at the middle of span decreases at the beginning of exposure to fire, although the bending moment in Model-P increases for the initial 15 minutes due to elongation of the slab. After 45 minutes, bending moment at the middle of span increases with decreasing flexural rigidity at the end of span. After 165 minutes, compression failure of concrete occurs in slab in the case of Model-P, and plastic hinges are created at the middle of span in both models. Due to the development of plastic hinges in the end and middle of span in both models, $\mathrm{H}$-shaped structural frames collapse. In such cases, the collapse time of each model is almost the same.

\section{CONCLUSIONS}

From the analyses, the following conclusions can be obtained.

Temperature distribution in the cross section of composite beams is generally that the highest temperature occurred in slab soffit, followed by the lower flange, then the web and then the upper flange. This temperature distribution causes the difference of structural behavior between steel beam and composite beam. The deformation of steel beam appears directly correspondent to temperature distribution in the cross section. On the other hand, at the beginning of fire exposure, the composite beam moves upward. And also, at the beginning of fire exposure, thermal expansion of slab soffit causes greater elongation of the composite beam than in the steel beam.

The influence of these behaviors can be seen in the analyses of $\mathrm{H}$-shaped structural frames. At the beginning of fire exposure, the bending moments at the end of the span of composite beam decrease, and the bending moment at the middle of span increases. And the bending moments at the restraint columns of composite beam are greater than that of steel beam. In spite of these differences between steel beam and composite beam, analyses of structural frames in this paper show that the fire resistance of structural frame with $\mathrm{H}$-section steel beam and the structural frame with composite beam is almost the same.

\section{REFERENCES}

[1] Article 107 in The Building Standard Law of Japan Enforcement Order

[2] Notification No.1675 of Ministry of Construction in Japan.

[3] Jding,R.H and Bresler,B,Effect of Fire Exposure on Steel Frame Buildings (Computer Model FASBUS II), Final Report wje 78124 Wiss, Janney, Elstner and Associates, Jnc., September 1981.

[4] CEC Research F210-SA/502-REFAO/CAFIR, Computer Assisted Analysis of the Fire Resistance of Steel and Composite Steel-Concrete structures (Computer Program CEFICOSS), Technical Reports RT 1-6, 1982/85.

[5] Wakamatsu, T, "Heat Flow Analysis of Building Members during Fire Exposure", First and Second Reports, Translation of the Architectural Institute of Japan. No.109 and 111, 1965. (in Japanese)

[6] Wakamatsu,T, "Heat Transfer during Fire Test", Bull. of the Fire Prevention Society of Japan, Vol.17 No.1, September 1967. (in Japanese)

[7] Wakamatsu,T, "Estimation of Fire Damage of Reinforced Concrete Beams", Fire Science and Technology, Vol.7, No.2, pp.1-16, 1987.

[8] Ministry of Construction in Japan, Development of Design System for Building Fire Safety, March 1987. (in Japanese)

[9] H.Saito, H.Uesugi, M.Yamaguchi and A.Kodaira, "Thermal Stress and Deformation of Steel Structures of High Rise Buildings in Fire", Fire Safety Science-Proceedings of the Second International Symposium, pp.719-728, 1989.

[10] Becker,J and Bresler,B , "Fires-RC A Computer Program for the Response of Structures Reinforced Concrete Frames", Report No.UCB FRG 74-3, University of California, Berkeley, July 1974. 